\title{
Study on Jingdong Company's Emergency Supply chain in the Context of Unconventional Emergency of Novel Coronavirus Pneumonia
}

\author{
Yonghui $\mathrm{CAO}^{1, \mathrm{a}}$, He JIANG ${ }^{* 1, \mathrm{~b}}$ \\ ${ }^{1}$ Department of Business Administration, Guangzhou College of Technology and Business, Guangzhou, China
}

\begin{abstract}
In 2020, the novel coronavirus pneumonia spread and raged around the world as a major unconventional emergency. The emergency supply chain management, which was not noticed by people, began to enter the vision of decision-makers. Novel coronavirus pneumonia is a key part of the new crown pneumonia epidemic. Jingdong, for example, illustrates how Jingdong constructs its emergency supply chain, with a view to providing some suggestions and references for the emergency supply chain to improve the urgent supply chain management.
\end{abstract}

\section{Introduction}

In 2020, the novel coronavirus pneumonia spread and raged around the world as a major unconventional emergency. The emergency supply chain management, which was not noticed by people, began to enter the vision of decision-makers. In fact, with the continuous demand of human beings for the natural environment, the frequency and intensity of various unconventional emergencies, such as major global epidemics, terrorist attacks, trade frictions and natural disasters, are increasing year by year. Unconventional emergencies make enterprises suffer losses such as production stop or supply shortage, which causes great harm to the normal operation of supply chain system.

With the development of economic globalization and information technology, the structure of supply chain is becoming more and more complex, and the scope of supply chain is becoming wider and wider. The development of modern information technology has brought great success to the supply chain, which also makes the ability of the supply chain system to resist uncertain events is greatly challenged. When the unconventional emergencies come, most enterprises are forced to interrupt their normal business, some even go bankrupt[1]. However, some enterprises can quickly recover from the unconventional emergencies and maintain high customer service. Practice has proved that the implementation of effective supply chain emergency management practice is helpful for enterprises to successfully deal with unconventional emergencies. However, there are few studies on how to deal with unconventional emergencies by constructing emergency supply chain at the enterprise level. Therefore, novel coronavirus pneumonia is a key issue in the new supply chain. Based on this, we take the Jingdong, a company that performs well in the new crown pneumonia epidemic, as an example. By explaining how Jingdong constructs its emergency supply chain, it hopes to provide some decision-making suggestions and references for all parties involved in the emergency supply chain, including logistics enterprises, it companies and government departments.

\section{Literature Review}

\section{1 theoretical basis}

Supply chain refers to a functional network chain structure that centers around the core enterprises, starting from the supporting parts, making intermediate products and final products, and finally delivering the products to consumers by the sales network, and connecting suppliers, manufacturers, distributors and end users into a whole. Supply chain management is simply the management of the relationship between supply and demand in the production process; it focuses on the production relationship (including logistics) between the parties involved in the whole network structure of products. The business philosophy of supply chain management is to seek the overall optimization of the supply chain from the perspective of consumers and through the cooperation between enterprises. Successful supply chain management can coordinate and integrate all activities in the supply chain, and eventually become a seamless integrated process.

Emergency supply chain management and enterprise supply chain management are similar but very different. The unconventional emergencies it faces are characterized by uncertainty in the time, place, type and impact scale of the event. Therefore, the matching degree between supply and demand fluctuates greatly. Emergency supply chain management is a process of efficiently and cost-effective

axinrui20132015@126.com, b*GZhappy2020@126.com 
transportation of materials (including food, water, medicine, etc.) from the production place to the disaster stricken areas through planning and implementation in the face of disasters and uncertainties, and effectively distribute and apply them to the disaster affected population. The contents of emergency supply chain management include: transferring people, raising, storing and handling large quantities of suitable materials, coordinating and sharing limited transportation capacity, and specific delivery of materials from outside the disaster area. The research on emergency supply chain at home and abroad mainly includes the strategies and models of supply chain system to deal with unconventional emergencies.

\section{2 strategies for emergency supply chain management to cope with unconventional emergencies}

Christopher, Tang and other scholars proposed two different emergency supply chain management strategies, resilience strategy and robust strategy[2].

(1) the ability of the supply chain to recover automatically after an emergency is measured. Flexibility strategy is characterized by the adaptability of supply chain system to environmental changes[3]. Flexible strategies include: postponement of manufacturing plan; combination of multiple "supply service" modes; flexible marketing strategy and sales price; information sharing and coordination of supply chain partners.

(2) Robustness means that the output of the system is stable for small input fluctuations. The robustness strategy includes: Strategic emergency inventory; standby supplier and emergency procurement; standardized product design, standardized plant layout and operation process[4].

\section{3 research on the model of emergency supply chain management responding to unconventional emergencies}

(1) Supply sector risk has attracted much attention.

Some scholars use decision tree and goal programming to establish a supplier quantity risk decision model with minimum operation cost and risk[5]. The research shows that standby supplier is an effective way to reduce the uncertainty of supplier's supply capacity. Some scholars have established a multi-level and multi supplier flexible supply chain network (multi-objective linear planning) model by introducing the reliability and expected tolerance service level of suppliers, considering the unit production cost of materials, unit transportation cost and fixed cost of supply channels[6]. Flexible supply chain network can reduce the impact of risk on supply chain system and improve the reliability of system output[7].

(2) Supply chain coordination is a hot topic in the research of supply chain management. Many scholars have studied it. For example, some researchers discuss how to adjust the order quantity and retail price to maximize the profit of the whole supply chain under the quantity discount contract when the market demand fluctuates due to emergencies.

\section{Case study}

\section{1 introduction to Jingdong Logistics}

Jingdong group started to build its own logistics in 2007, registered a logistics company in 2012, and formally established Jingdong Logistics Group on April 25, 2017. With the mission of reducing the cost of social logistics, Jingdong Logistics is committed to opening up the infrastructure, management experience and professional technology accumulated in the past decade to the society and become a global supply chain infrastructure service provider.

At present, Jingdong Logistics is the only enterprise in the world with six logistics networks of small and mediumsized parts, large pieces, cold chain, B2B, cross-border and crowdsourcing (dada). Relying on the global coverage of these six large networks and the application of big data, cloud computing and intelligent devices, Jingdong Logistics Co., Ltd, Jingdong Logistics has created embracing link from product sales analysis and prediction, to warehousing and delivery, to transportation and distribution, intelligent supply chain service system with the best comprehensive efficiency and the most scientific algorithm.

JD logistics operates more than 730 warehouses in China, including the cloud warehouse area of JD logistics management. The total storage area of JD logistics operation management is about 17 million square meters. Jingdong Logistics has realized almost $100 \%$ coverage of large and medium and small pieces network in mainland China, and $88 \%$ districts and counties can achieve 24-hour delivery. The operated distribution service covers $99 \%$ of the population in China, and more than $90 \%$ of the operated orders can be delivered within 24 hours. In recent years, the revenue of Jingdong Logistics and related business logistics and other businesses has increased by $98.1 \%$ yearon-year. As shown in Figure 1.

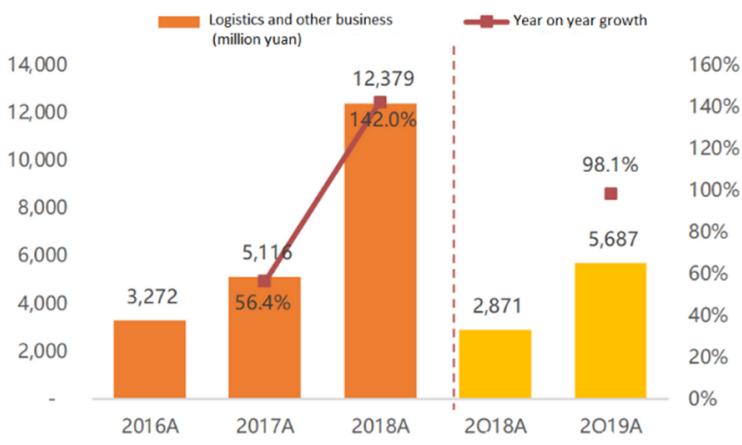

Fig1. Jingdong Logistics and other business year-on-year growth

\section{2 ecological construction of Jingdong supply chain}

Jingdong has always attached great importance to the ecological construction of the supply chain, and has made use of advanced information technology to build an intelligent supply chain platform. Three kinds of wisdom (visualization, perception and adjustment) are given to the 
three application scenarios (production, circulation and consumption) of modern supply chain. Among them, the Internet of things is the best solution for the visualization of modern supply chain. Things are connected to realize the intelligent identification, positioning, tracking, monitoring and management of the goods, which can build a close corresponding relationship between the information flow and the real logistics, and see the real supply chain through the Internet of things. Artificial intelligence is the best perceptible solution for the supply chain, because it provides big data decision-making, cloud computing services and machine learning algorithms, and can sense the laws and changes in the supply chain. Block chain is the best solution for modern supply chain adjustment. Decentralized smart contract solves the rigid constraints of supply chain, enables partners to quickly establish trust, without wasting time for inefficient game, and guides partners to spend more energy on how to compete with other supply chains in cost and efficiency, and provide optimal products and services for end customers The modern supply chain has the ability of dynamic adjustment.

The innovative application of three types of wisdom (visualization, perceivable and adjustable) completely covers the upstream and downstream of the supply chain, from the procurement of raw materials to the creative selection of products, design, research and development, production, pricing, product selection, inventory management, storage strategy and distribution optimization, and then to commodity marketing, trading and after-sales service. As shown in the figure below:

\section{3 emergency supply chain management of Jingdong in epidemic situation}

After the outbreak of novel coronavirus pneumonia, Jingdong has played an important role in ensuring normal supply of commodities, stabilizing prices to efficient logistics and distribution, and transporting key epidemic prevention materials. Jingdong has played an important role in ensuring the normal operation of the whole society. All these benefits from Jingdong's solid and mature emergency supply chain management system.

\subsubsection{Improve logistics speed based on big data analysis}

Relying on the supply chain platform technology, Jingdong Logistics, through big data monitoring and analysis as early as December 2019, paid attention to the obvious rise of mask sales and stock up data in Wuhan area at that time, which caused the attention of purchasing and marketing and logistics departments. The purchasing and marketing department made urgent follow-up, arranged the preparation of epidemic prevention materials such as masks, and arranged special personnel to follow up several brand manufacturers at the first time to ensure the increase of production capacity and supply. At the same time, relying on the warehouse network layout and big data analysis covering the whole country of Jingdong Logistics, the epidemic prevention materials with high demand of customers are put in the nearest warehouse to ensure that they are delivered to customers at the fastest speed.

\subsubsection{Strengthen technology investment and build emergency supply chain}

During the epidemic period, Jingdong cooperated with Hubei provincial government and formally contracted to build Hubei emergency supplies supply chain management platform. The platform is aimed at the production, inventory, allocation and distribution of protective clothing, masks, goggles and other materials urgently needed to fight the epidemic situation. It can track the production, inventory, allocation and distribution of materials urgently needed to fight the epidemic situation. It helps to accurately calculate, scientifically schedule and reasonably distribute the scarce medical materials in Hubei Province. Since Jingdong has continuously invested transportation capacity, human resources, unmanned equipment and other means to fully support Hubei Province, Jingdong has for the first time directly participated in the epidemic prevention and control work of government departments with supply chain technology. Because there are many kinds of anti-epidemic materials and different models, it is difficult to realize the timely matching between the first-line anti epidemic demand and material collection if the traditional way is adopted. In this case, Jingdong Logistics provides customized solutions for Hubei Province, integrating all data and information of anti-epidemic materials in digital form, and unified management by systematic supply chain platform, so as to provide strong logistics support for the fight against epidemic. The Hubei emergency supplies supply chain management platform has achieved two goals: first, through the information-based and intelligent supply chain platform, the emergency materials can be collected in a data and systematic way. The front-end can process more complex material information input, and the backend can connect with different logistics data. At the same time, the information flow can be more perfect and visible to ensure the openness and transparency; second, the front-end procurement, the front-end procurement, and the back-end can connect with different logistics data The big data management of inventory management and goods flow direction realizes the integration of warehousing, outbound, signing in, acceptance, review, audit and other links and processes, so as to facilitate the allocation and management of materials and improve the efficiency of material processing.

\subsubsection{Making use of artificial intelligence to ensure residents' life}

Due to the closure of Wuhan City, how to meet the daily life of the citizens once became the focus of the whole country. Relying on the technical advantages, Jingdong Logistics carries out the overall allocation of national transportation capacity and distribution capacity. With the help of big data analysis and prediction technology, the "intelligent brain" can accurately dispatch the transportation capacity of the whole network, and 
excavate the historical orders, population distribution and future order rules in the epidemic area, and take the initiative to meet the orders of key hospitals in Wuhan, and make the warehouse of Jingdong logistics become a stable material warehouse in the fight against the epidemic. At the same time, in the case of overall traffic obstruction, JD logistics organized the whole network logistics resources in a short time to help complete the matching between the national material transportation and transportation capacity, and concentrate the transportation capacity to complete more material transportation. After the materials were transported to Wuhan, JD logistics completed the distribution map collection and robot test in Wuhan Based on the supply chain technology platform, and put the unmanned distribution vehicle into the front line of epidemic prevention.

In addition, due to the road transportation obstruction, some agricultural products are faced with the situation that they cannot be sent out of the village. In order to solve the problem of "the first one kilometer" of fresh products, Jingdong Logistics took the lead in launching the "mobile vegetable basket" program. On the one hand, it linked vegetable and fruit production and planting enterprises and farmers to provide direct purchase and direct sales service for fresh products in the production area, and built a direct supply channel of "direct marketing + logistics transportation" to help agricultural products go up; on the other hand, it created an online purchase platform to guarantee delivery services. At present, Jingdong Logistics "mobile vegetable basket" program has been implemented in nearly 50 cities across the country, collecting nearly 350 tons of agricultural products a day.

\section{Conclusion}

Based on the above analysis, it can be seen that the effective implementation of emergency supply chain management of Jingdong is inseparable from the deep "internal power" of Jingdong digital supply chain. Jingdong started the construction of intelligent supply chain very early. The excellent flexibility and flexibility of Jingdong's digital supply chain showed a significant advantage in the epidemic situation. From the supply chain to the digital supply chain, the rapid response of Jingdong supply chain makes it highlight its advantages in communicating with major brand suppliers, entering warehouse of self operated products and ensuring stable supply of goods. At the same time, with the supply chain network covering the whole country established over the years, Jingdong has made timely response in the aspects of production coordination, price monitoring, distribution guarantee and platform construction, which has effectively guaranteed the "lifeline" of key epidemic prevention materials transportation. In order to ensure the safety and convenience of the "last mile" receiving and sending service, Jingdong Logistics gives full play to the advantages of intelligent technology and diversified ecology, and provides more than ten kinds of "contactless" express delivery services, such as self delivery cabinet, convenient service point, intelligent distribution robot. Jingdong's performance during the epidemic period is mainly based on Jingdong's accumulated supply chain, logistics and technical capabilities for many years. Especially after Jingdong continues to increase technological research and development, the anti-risk ability of supply chain and logistics system has been significantly improved.

The main experiences are as follows: The comprehensive emergency management system should realize the comprehensive emergency management guarantee from the aspects of organization system, operation mechanism, legal basis and guarantee system. According to the inventory and production capacity of emergency materials, the management means of emergency dispatch and real-time response are adopted to establish the supply mode of real-time response and quick landing from the centralized and batch overall supply of various regions. It should build a timely response logistics system: unified emergency logistics dispatching command center, the government's overall planning and dispatching, easy access to mass resources, and centralized dispatching of people, vehicles, goods, fields and roads, green channels and specialized teams. Company Established a unified monitoring and analysis platform: combined with cloud computing, big data, block chain and artificial intelligence technology, based on relevant data, combined with government, donors, public welfare organizations, logistics parties, suppliers and other public information, to realize the emergency logistics system, supply resources, transparent credit value flow of supply and demand.

Through the analysis of Jingdong emergency supply chain management case, we can see that digital technology and big data play an important role in ensuring the rapid response and agile supply of the emergency supply chain, and the application of automation and unmanned equipment is also indispensable. These will become the new trend of supply chain development, and will also be the supply chain participants of other logistics enterprises, IT companies, government departments, etc. To improve the emergency supply chain management, we should pay attention to and strive to achieve the important links.

\section{Acknowledgment}

This work is financially supported by outstanding scholars of philosophy and Social Sciences in Henan Province higher education in 2018, 2018-YXXZ-06; Henan philosophy and Social Sciences Planning Project in 2019, 2019BJJ003; The social development project of Henan provincial key R \& D and promotion project (Science and technology tackling key problems) in 2019, project number: 515; The science and technology innovation talent support program project of Henan Province higher education (HUMANITIES AND SOCIAL SCIENCES) in 2017, 2017-cxrc-004; Foshan social science planning project in 2020, 2020-QN11. Thanks for the help.

\section{References}

1. Zhao Yanqiu. The "strongest brain" of Jingdong supply chain [J]. It manager world, 2017 (6): 53-55

2. Tang C, Kay R M, Skaggs D L, et al. Growth arrest of 
the distal radius following a metaphyseal fracture: case report and review of the literature.[J]. Journal of Pediatric Orthopaedics B, 2002, 11(1): 89-92.

3. Holguinveras J, Perez N, Ukkusuri S V, et al. Emergency Logistics Issues Affecting the Response to Katrina: A Synthesis and Preliminary Suggestions for Improvement[J]. Transportation Research Record, 2007, 2022(2022): 76-82.

4. Ji G, Zhu C. A Study on Emergency Supply Chain and Risk Based on Urgent Relief Service in Disasters[J]. Systems Engineering Procedia, 2012: 313-325.

5. Chern C, Chen Y L, Kung L, et al. A heuristic relief transportation planning algorithm for emergency supply chain management [J]. International Journal of Computer Mathematics, 2010, 87(7): 1638-1664.

6. Dasaklis T K, Rachaniotis N, Pappis C P, et al. Emergency supply chain management for controlling a smallpox outbreak: the case for regional mass vaccination[J]. International Journal of Systems Science: Operations \& Logistics, 2017, 4(1): 27-40.

7. Patelanita, Dalessandromaryann M, Irelandkaren J, et al. Personal Protective Equipment Supply Chain: Lessons Learned from Recent Public Health Emergency Responses[J]. Health security, 2017, 15(3): 244-252. 